\title{
Mechanical and Microstructural Characterization of Nodular Cast Iron (NCI) with Niobium Additions
}

\author{
Tânia Nogueira Fonseca Souza ${ }^{a, b *}$, Rogéria Alves Perilo Sousa Nogueira ${ }^{c}$, \\ Francis José Saldanha Franco ${ }^{b}$, Maria Teresa Paulino Aguilard, Paulo Roberto Cetlin ${ }^{a}$ \\ ${ }^{a}$ Department of Mechanical Engineering - DEMAT, Universidade Federal de Minas Gerais - UFMG, \\ Av. Antônio Carlos, 6627, Pampulha, CEP 31270-901, Belo Horizonte, MG, Brazil \\ ${ }^{b}$ Department of Mechanical Engineering - DEMAT, Universidade de Itaúna - UIT, Rodovia MG 431, \\ Km 45 (Trevo Itaúna/Pará de Minas), CP 100, CEP 35.680-142, Itaúna, MG, Brasil \\ ${ }^{c}$ Centro Tecnológico de Fundição - SENAI/CETEF, Rua Lilia Antunes, \\ 99, CEP 35680-270, Itaúna, MG, Brasil \\ ${ }^{d}$ Department of Materials and Construction, Universidade Federal de Minas Gerais - UFMG, \\ Av. Antônio Carlos, 6627, Pampulha, CEP 31270-901, Belo Horizonte, MG, Brazil
}

Received: October 31, 2013; Revised: October 14, 2014

\begin{abstract}
Nodular cast irons (NCIs) involve the inoculation and nodulization of 0.03 to $0.06 \mathrm{wt} \%$ Magnesium, as well as the addition of Molybdenum, Chromium, Nickel, Copper and Vanadium, although the presence of Niobium is not common. The literature reports that Niobium leads to better mechanical properties of the NCIs, and recent results indicate that $0.5 \mathrm{wt} \%$ Niobium increases the strength and the Charpy notch toughness of NCIs, but decreases its hardness, in relation to a similar NCI without Niobium. The present report studies the addition of $0.23,0.47,0.67$, and $0.85 \mathrm{wt} \%$ Niobium to a NCI covering the effects on the microstructures, yield and tensile strengths, tensile elongations and Charpy toughness. The NCIs were prepared in a $120 \mathrm{~kg}$ medium frequency induction furnace, and samples were obtained following the ASTM A842 standard; the various test specimens were extracted from these samples according to specific standards for each test. Fracture analysis was performed in fractures specimens after the Charpy tests. It was shown that the volume fraction of pearlite increases as the Niobium content is raised, leading to increments in the yield and tensile strengths and hardness of these materials. Modest increment of tensile ductility and Charpy toughness are observed only for an addition of $0.23 \%$ Niobium. Fracture analysis revealed typical brittle cleavage surfaces and decohesion between grains and grain - graphite nodules interfaces, and very low porosity
\end{abstract}

Keywords: Nodular Cast Iron (NCI), Niobium, microstructure, mechanical properties

\section{Introduction}

Nodular Cast Iron (hereafter called "NCI") is an engineering material displaying high ductility, elastic modulus, mechanical strength and corrosion resistance; in addition, it has low cost and is easy to produce and machine $^{1}$, and is thus widely used as a structural material. During the last years the industrial use of NCIs iron has been increasing and many investigations on the characterization and improvement of its mechanical properties have been developed $^{2}$. Examples of the use of NCIs are automotive parts such as camshafts, crankshafts, water pump housings, valves and steering articulations $\mathrm{s}^{3,4}$.

The spheroidal graphite nodules distributed in the ferrite and/or pearlite matrix of NClis obtained through Magnesium inoculation; other alloying elements such as Copper, Chromium, Nickel, Vanadium and Molybdenum are also commonly added to NCIs in order to obtain specific properties ${ }^{3,5,6}$. Molybdenum enhances the austempering of NCIs, improving their wear resistance, but causing

*e-mail: tnfsouza@gmail.com an increase in their hardenability and thus restricting the manufacturing of parts with thin walls. Molybdenum also leads to the formation of intracellular carbides, drastically reducing the tensile elongation of NCIs ${ }^{7}$. Guesser et al. ${ }^{8,9}$ and Nylen ${ }^{10}$ showed that the presence of Niobium and Titanium in NCIs improves their tensile strength and hardness. Frás et al. ${ }^{11}$ evaluated the influence of small additions of Vanadium and Niobium (less than $0.04 \mathrm{wt} \%$ ) on the tensile properties of cast irons, and concluded that Niobium is less deleterious than other alloying elements with regard to the decrease in the tensile elongation of the material. A recent study by Abdullah et al. ${ }^{12}$ shows that the addition of $0.5 \%$ Niobium to NCIs leads to a lower hardness than for the same material without the presence of Niobium, and to an increase in the material strength and Charpy impact energy absorption. Vatavuk and Mariano ${ }^{13}$ analyzed the effect of $0.5 \%$ Niobium on the hot wear resistance of NCIs. Cueva et al. ${ }^{14}$ studied the effect of Niobium and Vanadium in grey cast iron on its wear resistance and reported an 
increase in the material wear resistance as a consequence of the alloying with Niobium the friction as well as Frás et al. ${ }^{11}$.

The presence of Niobium in NCIs leads to the formation of polygonal and eutectic Niobium carbides, whose morphology must be controlled, since their agglomeration and the presence of coarse carbides compromise the mechanical properties of the material ${ }^{11,15}$. The dissolution of Niobium in NCIs seems to be difficult and studies indicate that this is linked to the low working temperature and to the high Carbon content of cast irons ${ }^{15,16}$.

The present study investigates the influence of a range of Niobium contents $(0.23$ to $0.85 \mathrm{wt} \%)$ on the microstructure, mechanical strength, Charpy toughness and ductility of NCIs. A fracture analysis is also presented. The authors are not aware of any similar studies in the literature.

\section{Experimental Procedures}

The NCIs were obtained from a base material to which were added target levels of $0.2 \% ; 0.4 \% ; 0.6 \%$ and $0.8 \%$ Niobium as ferro-niobium. A $120 \mathrm{~kg}$ medium frequency induction furnace was employed, involving a special casting technique, in order to avoid the presence of undissolved Niobium nuclei and the formation of coarse carbides in the material. The ferro-niobium had a granulometry of $3-6 \mathrm{~mm}$ and was added to the liquid base material at temperatures initially around $1360^{\circ} \mathrm{C}$, under strong manual agitation. As suggested by Silva ${ }^{15}$, Vatavulk and Mariano ${ }^{13}$, this led to a homogeneous distribution of Niobium carbides in the final NCI microstructure. Adequate dissolution conditions were reached for a temperature of $1480^{\circ} \mathrm{C}$ and an agitation time of 10 to 15 min leading, however, to a large amount of slag. The chemical composition of the material was monitored by optical spectrometry during melting. The inoculation treatment was performed with FeSi and the nodularization treatment with FeSiMg. The "sandwich" method was utilized, which consists in placing the nodularization and the inoculation alloys in the bottom of the pouring ladle, and then transferring the molten metal from the furnace into the ladle. The samples were produced in conventional furanic resin sand molding process. Type $\mathrm{Y}$ specimens were produced for tensile tests, type $\Omega$ specimens for the metallographic evaluation ${ }^{17}$ and pins $(86 \mathrm{~mm}$ long, gauge diameter of $16 \mathrm{~mm}$ and a gripping head with a diameter of $20 \mathrm{~mm}$ ) for the wear tests ${ }^{18,19}$. The specimens were stripped 12 hours after pouring, cleaned and then cold cut to pieces whose size was adequate for the machining of the various testing samples.

The metallographic preparation of specimens involved standard grinding followed by polishing and etching with Nital 2\%. The microstructural characterization of the NCIs employed optical microscopy (UNION - Versamet - 2 microscope) and scanning electronic microscopy (SEM - JEOL JSM-6510LV, including chemical microanalysis with an energy dispersion system - EDS). The quantitative image analysis utilized the HL Image 2001 image software. Fracture analysis was performed with the same scanning electron microscope.

The tensile tests ( 8 tests per sample) were performed in a $200 \mathrm{kN}$ capacity universal mechanical testing machine. Hardness tests (24 measurements for each sample) were performed in a semi-automatic Brinell durometer (Heckert - 3000D, load of 1838,7 N and a spherical indenter with diameter $2.5 \mathrm{~mm}$ ) according to ASTM standards ${ }^{17-19}$ and Charpy impact testing was performed according to the ASTM-A327 standard $^{20}$.

\section{Results and Discussion}

Table 1 shows the chemical composition of the various NCIs obtained. The final Niobium content in the various materials was somewhat higher than the intended target values.

Quantitative metallography indicated a volume fraction of $39 \%$ for pearlite, $61 \%$ for ferrite and less than $1 \%$ of Niobium carbides. Sulfides and Phosphorus compounds (steadite) were also detected in the samples. The nodularization level was $91 \pm 0.46 \%$, with $412 \pm 1.38$ spheroids $/ \mathrm{mm}^{2}$. Such results indicate that the material is typical ductile $\mathrm{NCI}^{3,7,12}$.

Computer simulations of the solidification (utilizing the Magmasoft software) were performed for the various obtained chemical compositions, in order to determine whether hypo or hipereutectetic solidification occurred; no situation where the presence of primary phases such as graphite and austenite were predicted. One can thus infer that the equivalent Carbon variations (covering the joint effect of Carbon and Silicon) in the various alloys did not affect the final microstructures. The Manganese, Phosphor, Magnesium and Sulfur contents were practically constant. The residual elements were also within acceptable limits ${ }^{21}$ and one concludes that chemical composition variations are basically associated with the Niobium content.

Figure 1 shows the microstructure of the NCI without Niobium. Typical dark, spheroidal nodules of graphite are observed, embedded in ferrite regions (light areas) and a pearlite matrix (dark areas).

Table 2 displays the microstructural results for the various NCIs with Niobium additions. It can be seen that the reported microstructures features are qualitatively similar to those in Figure 1, but with marked quantitative differences.

Table 1. Chemical composition of the NCIs ( $w t \%)$.

\begin{tabular}{ccccccc}
\hline $\mathbf{C} \%$ & Si\% & Mn\% & P\% & S\% & Mg\% & Niobium\% \\
\hline 3.74 & 2.67 & 0.23 & 0.096 & 0.013 & 0.038 & 0.001 \\
3.39 & 2.76 & 0.24 & 0.101 & 0.016 & 0.040 & 0.230 \\
3.63 & 2.64 & 0.25 & 0.092 & 0.009 & 0.039 & 0.471 \\
3.64 & 2.62 & 0.23 & 0.089 & 0.009 & 0.037 & 0.671 \\
3.32 & 2.57 & 0.23 & 0.085 & 0.008 & 0.034 & 0.852 \\
\hline
\end{tabular}


Figure 2 displays the variation of the volume fraction of pearlite, ferrite, graphite and carbides of the samples with the Niobium content. The graphite fraction includes nodules associated with oxides, sulfides, micro-shrinkages and other inclusions, since it was impossible to separate these various features. The addition of Niobium promotes an increase in the amount of pearlite in NCIs up to about $0.7 \%$ Niobium, followed by a decrease for $0.8 \%$ Niobium. The volume fraction of ferrite varies in the inverse proportion to that of pearlite.

The volume fraction of carbides was approximately constant at a level of less than $1 \%$ up to about $0.4 \%$ Niobium, rose up to $5.3 \%$ for Niobium contents of about $0.6 \%$ and then returned to $1.1 \%$ for an addition of $0.8 \%$ Niobium. This was probably caused by the formation of other carbides, in addition to the Niobium ones, since some EDS results indicated the presence of carbides with a low or non-extant level of Niobium. It is noteworthy that the distribution of carbides was not homogenous.

Figure 3 displays a typical SEM image for the materials in this research, where the presence of Niobium rich precipitates, carbides and carbo-nitrides, could be identified $^{16}$. Their typical semi-quantitative and approximate chemical composition was $56 \%$ Niobium, $23 \% \mathrm{C}, 8 \% \mathrm{~B}$ (originally present in the Ferro-Niobium, according to a chemical analysis performed in this material) $4 \% \mathrm{O}, 2 \% \mathrm{Ti}$, $8 \% \mathrm{Fe}$ and residues of $\mathrm{Si}, \mathrm{Al}, \mathrm{P}$ and $\mathrm{V}$. The carbides were distributed in the matrix and had trapezoidal or rectangular shapes, similarly to those reported in the literature, and the improvement in the hot wear of NCIs with $0.5 \%$ Niobium has been attributed to the presence of these carbides ${ }^{9,12,14,22,23}$. The sample matrix was Niobium free, probably due to its low Niobium solubility ${ }^{10,22,23}$. It is however believed ${ }^{12,22}$ that a small amount of Niobium would be present in the matrix, interfering on the kinetics of the eutectic reaction and promoting the formation of a greater amount of pearlite, which was indeed observed in the present case, for specimens with up to $0.6 \%$ Niobium (see Figure 3).

Figure 4 indicates that the addition of Niobium to NCIs leads to an increase in their yield and tensile strengths. The maximum effect (an increase of $20 \%$ over the values for the Niobium-free NCI) occurs at around $0.6 \%$ Niobium. This is associated with the increase in pearlite content of the NCIs as the Niobium content is raised ${ }^{23}$ as indicated in Figure 2.

The tensile elongation of the NCIs tends to decrease with the increase in Niobium content (see Figure 4); it is noteworthy that there is a small increase in this elongation as a result of a $0.2 \%$ Niobium addition, which may be caused by the improvement in the nodularization level $(80 \%$ for the Niobium free NCI and $85-95 \%$ for the NCIs with additions of Niobium).

Figure 5 displays the results for the Charpy energy measurements at room temperature (notchless samples) for the various NCIs in this research. There is an increase in the absorbed energy for an addition of $0.23 \%$ Niobium, followed by steadily decreasing energies as the Niobium content is raised. A possible reason for this can be the initial increment in number of graphite spheroids $/ \mathrm{mm}^{2}$ up to $0.23 \mathrm{wt} \%$ Niobium, followed by decreasing contents of graphite for higher Niobium levels (see Figure 3), since the

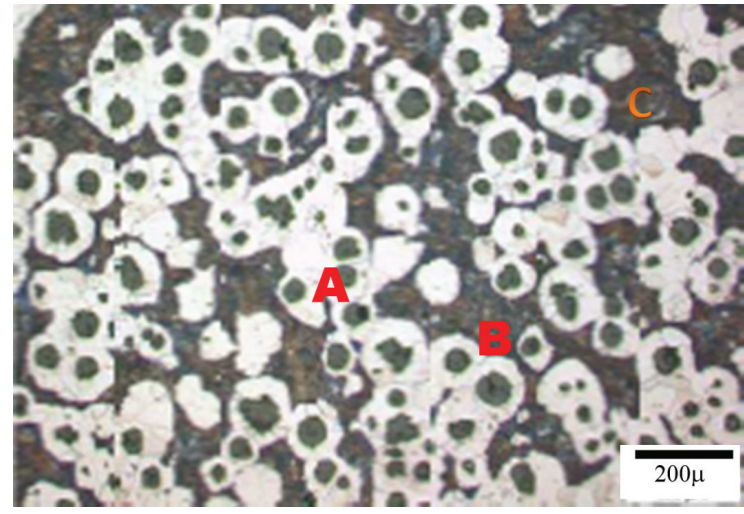

Figure 1. Microstructure of the NCI without Niobium (A = Ferrite, $\mathrm{B}=$ Graphite, $\mathrm{C}=$ Pearlite - optical microscopy).

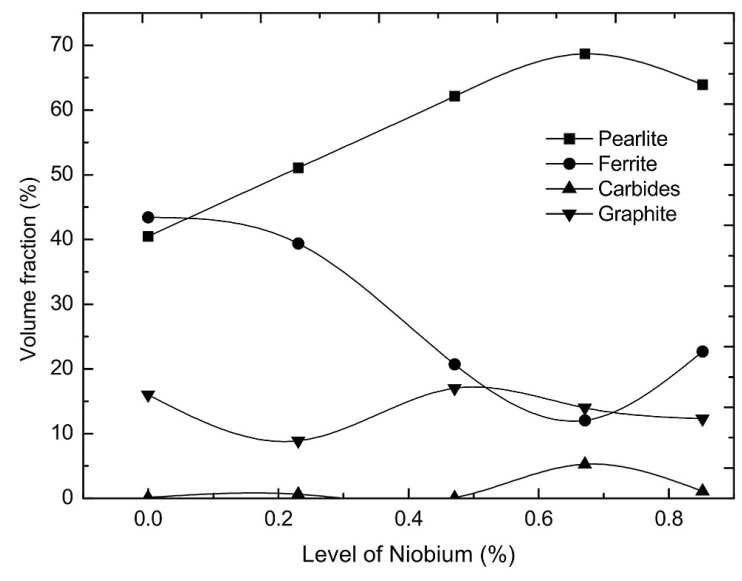

Figure 2. Variation of the volume fractions of pearlite, ferrite, carbides and graphite in NCIs for various Niobium contents.

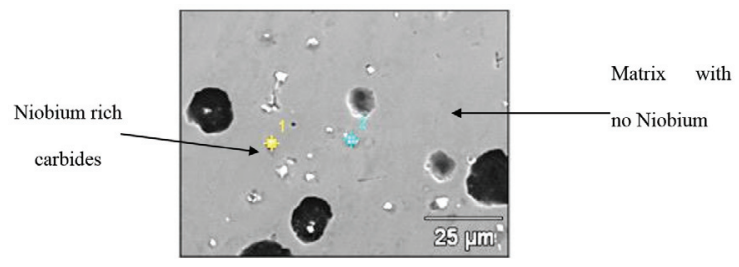

Figure 3. Typical microstructure of a NCI with Niobium (SEM; EDS analysis at points 1 and 2).

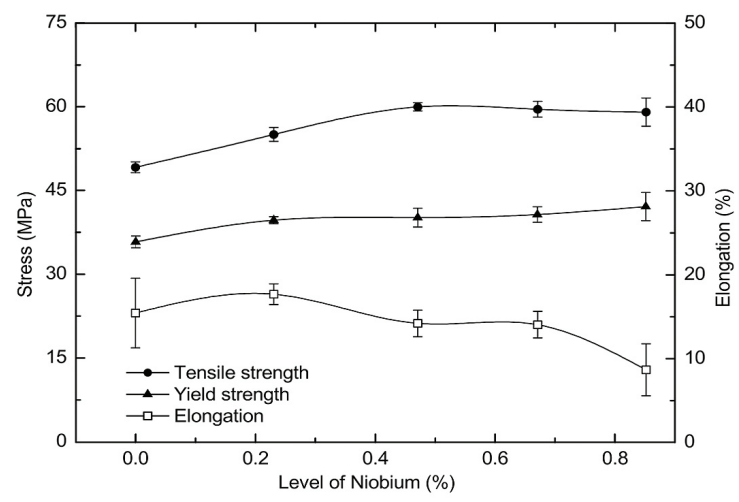

Figure 4. Yield strength, tensile strength and elongation for NCIs with various Niobium additions. 
Table 2. Characterization of NCIs with Niobium (optical microscopy).

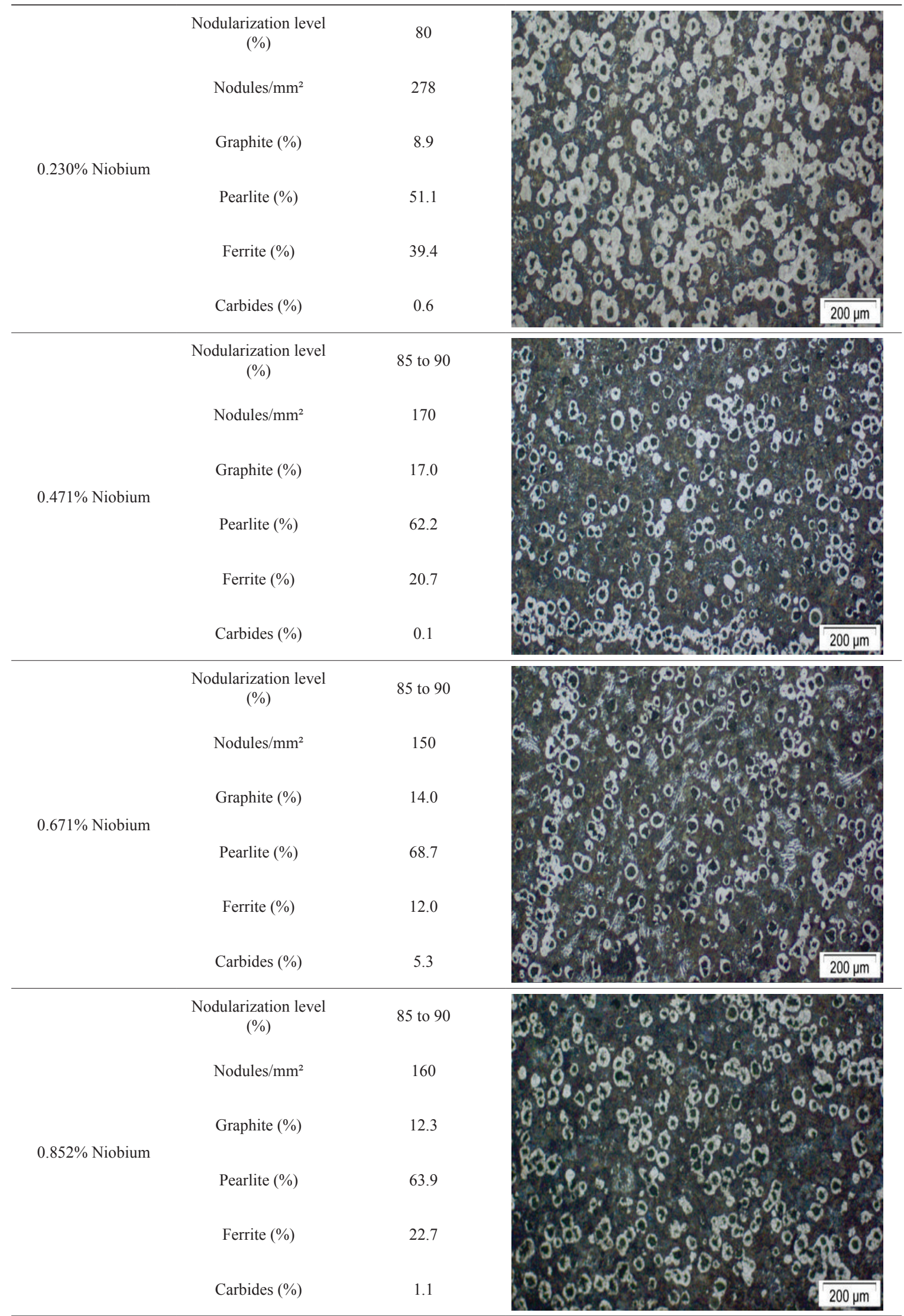




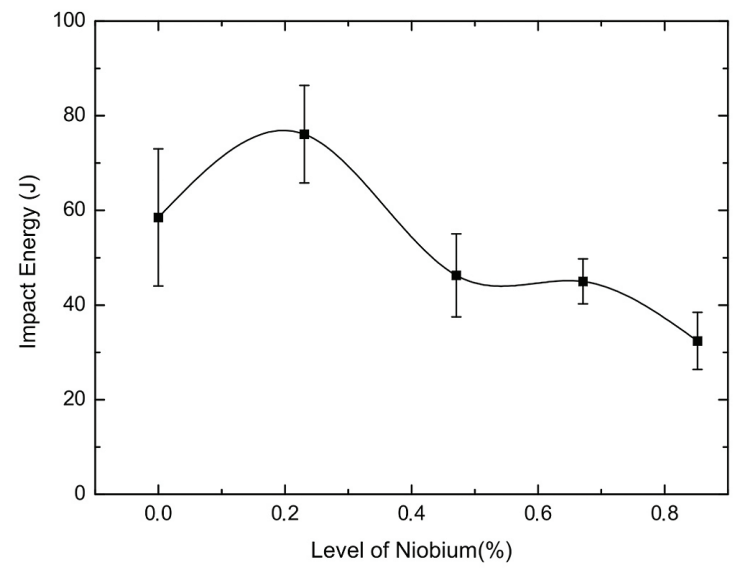

Figure 5. Changes in the Charpy energy of NCIs for various levels of Niobium additions.

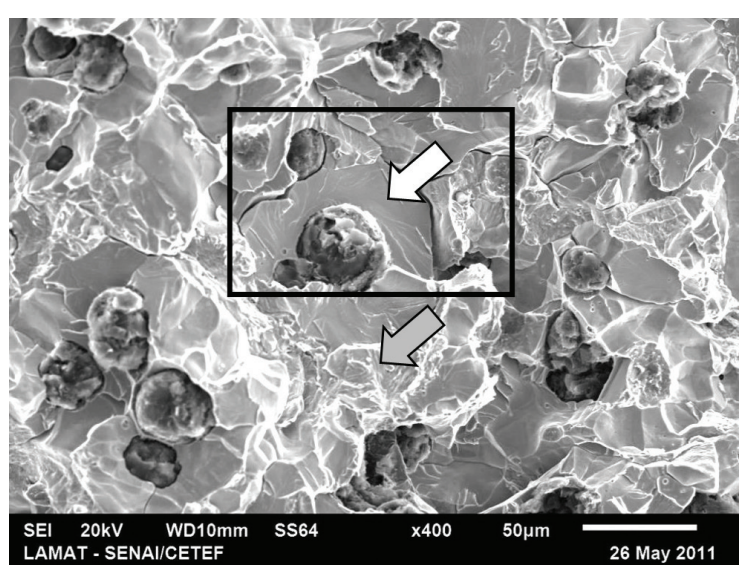

Figure 6. Fracture surface of broken Charpy test specimen.

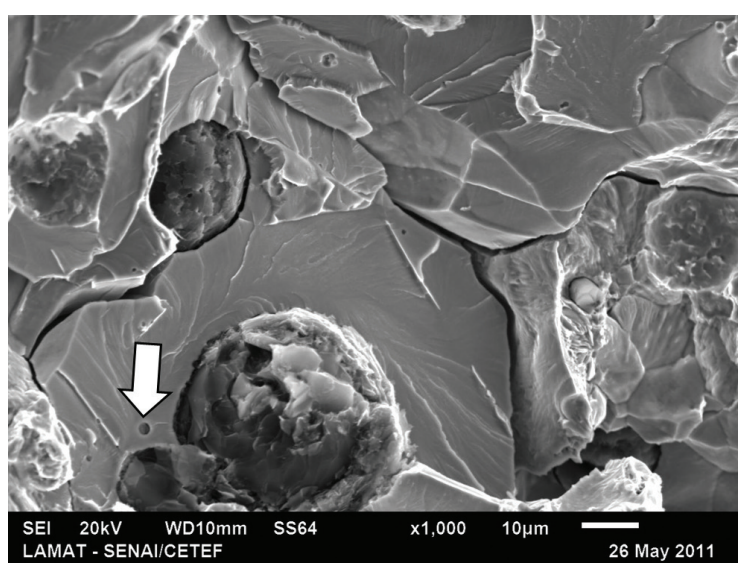

Figure 7. Magnification of the central part of Figure 6 (indicated by the rectangle). mechanical properties of NCIs are enhanced for a higher number of spheroids per square millimeters ${ }^{24}$. An increase in the Charpy energy of a NCI containing Nickel and Copper, for an addition of $0.5 \%$ Niobium, has been observed, but it is however not clear whether specimens with or without notches were utilized; it is noteworthy that the present energy values are appreciably higher than those reported in the literature ${ }^{23}$.

Figure 6 displays the typical aspect of the fracture surfaces of Charpy specimens, which were very similar for all Niobium contents in the present study. The white arrow points to a typical cleavage facet observed in the planes normal to the applied tensile stresses. For fracture planes approximately parallel to the applied normal stresses, the presence of diffuse dimples, typical of shear fractures, is observed. Figure 6 also indicates the profuse decohesion between the matrix and the graphite nodules and between the matrix grains. Figure 7 is a magnification of the central rectangle in Figure 6, where the above described features can be clearly observed. In addition, the micropore (indicated by a white arrow) in Figure 7 seems to have had a very limited influence on the development of the fracture.

\section{Conclusions}

The increase in Niobium additions to NCIs affects their microstructures and mechanical properties. The maximum values of ductility were reached for a Niobium content of $0.23 \%$, which also caused an increase in other mechanical properties of the material, in relation to those for NCIs without Niobium additions.

Both yield and tensile strengths of NCIs increase as the Niobium additions were raised; tensile strength did not increase appreciably above $0.47 \%$ Niobium, but yield strength increased slowly up to $0.85 \%$ Niobium.

An interesting combination of properties was reached for $0.23 \%$ Niobium, associated with increases in tensile and yield strengths and a slight decrease in elongation, in relation to the material without Niobium additions.

Additions of Niobium to NCIs promoted precipitation of Niobium compounds in the castiron matrix; the Niobium content of $0.67 \%$ led to the maximum precipitation.

The fracture analysis of the Charpy specimens indicated the presence of cleavage facets and profuse decohesion between the matrix and the graphite nodules, as well as between the matrix grains. Micropores seem to have a very limited effect on the fracture.

\section{Acknowledgements}

The authors are indebted to Companhia Brasileira de Metalurgia e Mineração - CBMM for providing samples of FerroNiobium. Finantial support for the present research by CNPq, CAPES, FAPEMIG, Graduate Programs in Metallurgical and Mining and in Mechanical Engineering of UFMG is gratefully acknowledged. 


\section{References}

1. Hernández-Riviera JL, Campos Cambranis RE and Garza A. Study of microstructural evolution and mechanical properties exhibited by non alloyed ductile iron during conventional and stepped austempering heat treatment. Materials \& Design. 2011; 32(10):4756-4762. http://dx.doi.org/10.1016/j. matdes.2011.06.030.

2. Fiero VE, Sikora JA, Agüera FR, Aillar HNA, Ansaldi AF and Ratto PJJ. Fractomechanical properties of as-cast and austempered SG cast iron between $-40^{\circ} \mathrm{C}$ and $+20^{\circ} \mathrm{C}$. Materials Research. 2002; 5(2):137-141.

3. Toktas G, Tayanç M and Toktas A. Effect of matrix structure on the impact properties of an alloyed ductile iron. Materials Characterization. 2006; 57(4-5):290-299. http://dx.doi. org/10.1016/j.matchar.2006.02.008.

4. Orlowicz W, Tupaj M, Mróz M and Guzik E. Evaluation of ductile iron casting material quality using ultrasonic testing. Journal of Materials Processing Technology. 2010; 210(11):1493-1500. http://dx.doi.org/10.1016/j. jmatprotec.2010.04.007.

5. Yoon-Jun K, Jang $\mathrm{O}$ and Yong-Jun O. High-temperature low-cycle fatigue property of heat-resistant ductile-cast irons. Metallurgical and Materials Transactions. 2009; 40(9):20872097.

6. Cheng-Hsun H, Yih-Hsun S, Yuan-Hsin Y and Shen-Chih L. Effect of austempering heat treatment on fracture toughness of copper alloyed gray iron. Materials Chemistry and Physics. 2000; 63(1):75-81. http://dx.doi.org/10.1016/S02540584(99)00213-8.

7. Mattar AR Jr. Influência dos elementos de liga $\mathrm{Cu}-\mathrm{Ni}-\mathrm{Mo}$ nas propriedades mecânicas e austemperabilidade do ADI. [Dissertação]. São Carlos: Universidade de São Paulo; 2009.

8. Guesser WL. Propriedades Mecânicas dos Ferros Fundidos. São Paulo: Editora Bucher; 2009.

9. Guesser WL and Guedes LC. Desenvolvimentos recentes em ferros fundidos aplicados à indústria automobilística. In: Seminário da Associação de Engenharia Automotiva; 1997; São Paulo, Brasil. São Paulo: AEA; 1997.

10. Nylen T. A adição de Nióbio em ferros fundidos. Fundição $e$ Serviços. 2007; 17(177):72-87.

11. Frás EM, Górny M and Kawalec M. Effect of small additions of vanadion and niobium on structure and mechanical properties of ductile iron. Archives of Foundry Engineering. 2007; 89-92.
12. Abdullah B, Siti K, Ahmed J., Freddawati R and Wong AR. Mechanical properties and microestruture analysis of $0,5 \%$ Niobium alloyed ductile iron under austempered process in salt bath treatment. In: International Conference on mechanical and electrical technology; 2010; Singapore. Singapore: ICMET; 2010. p. 610-614.

13. Vatavuk J and Mariano JR. Wear resistant nodular iron for piston rings. Revista Mackenzie de Engenharia e Computação. 1998; 3(3):71-85.

14. Cueva G, Sinatora A, Guesser WL and Tschiptschin AP. Ferros fundidos empregados em discos e tambores de freio. In: Brake Colloquiom - SAE Brasil; 2003; Brasil; 2003. p. 1-6.

15. Silva RCSC. Dissolução de ferronióbio em ferro fundido. [Dissertação]. São Paulo: Universidade de São Paulo; 2000.

16. Pérez RA, Gas P and Maugis P. Study of diffusion and reaction diffusion in Fe-C-Nb system. Trans Tech Publications. 2007; 264:163-169.

17. American Society for Testing and Materials - ASTM. ASTM A842M: standard specification for compacted grafithe iron casting. ASTM; 2011.

18. American Society for Testing and Materials - ASTM. ASTM A897M: standart specification for austempered ductile iron casting. ASTM; 2006.

19. American Society for Testing and Materials - ASTM. ASTM A536M: standart specification for ductile iron casting. ASTM; 1984.

20. American Society for Testing and Materials - ASTM. ASTM A327M: standarttest methods for tension testing of metallic materials. ASTM; 2006.

21. Lussoli RJ. Efeito da adição de cobre e da seção da peça sobre as características microestruturais e mecânicas de ferro fundido nodular austemperado. [Tese]. Florianópolis: Universidade Federal de Santa Catarina; 2003.

22. Abdullah B, Siti KA, Jaffar AJ, Rashid AA, Haskil M and Ramli A. Tensile strength of Niobium alloyed austempered ductile iron on different austempering time. Advanced Materials Research. 2012; 457-458:1155-1158.

23. Bedolla AJ, Solis E and Hernandez B. Effect of niobium in medium alloyed ductile cast irons. International Journal of Casting Metal Research. 2003; 5:1-6.

24. Silva C. Influência do número de nódulos de grafita nas propriedades mecânicas do ferro fundido nodular austemperado. [Dissertação]. Belo Horizonte: Universidade Federal de Minas Gerais; 2005. 